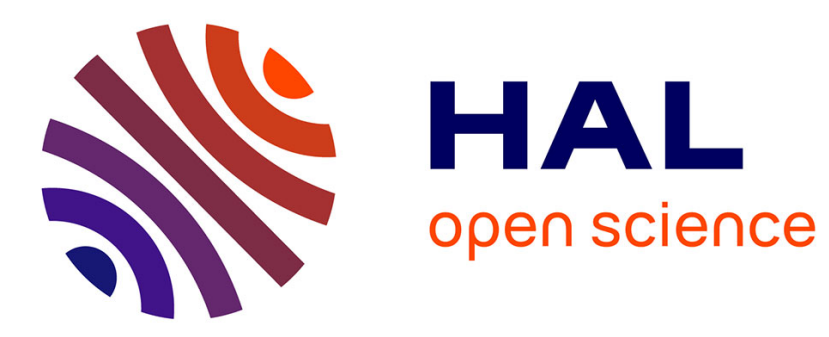

\title{
Evaluation of T-wave Morphology Parameters in Drug-Induced Repolarization Abnormalities
}

Nadine Khodor, Guy Carrault, Hassan Amoud, Mohamad Khalil, Philippe L'Hostis, Alfredo I. Hernandez

\section{- To cite this version:}

Nadine Khodor, Guy Carrault, Hassan Amoud, Mohamad Khalil, Philippe L'Hostis, et al.. Evaluation of T-wave Morphology Parameters in Drug-Induced Repolarization Abnormalities. 2nd International Conference on Advances in Biomedical Engineering (ICABME), Sep 2013, Tripoli, Lebanon. pp.203 206, 10.1109/ICABME.2013.6648883 . hal-00881382

\section{HAL Id: hal-00881382 https://hal.science/hal-00881382}

Submitted on 8 Nov 2013

HAL is a multi-disciplinary open access archive for the deposit and dissemination of scientific research documents, whether they are published or not. The documents may come from teaching and research institutions in France or abroad, or from public or private research centers.
L'archive ouverte pluridisciplinaire HAL, est destinée au dépôt et à la diffusion de documents scientifiques de niveau recherche, publiés ou non, émanant des établissements d'enseignement et de recherche français ou étrangers, des laboratoires publics ou privés. 


\title{
Evaluation of T-wave Morphology Parameters in Drug-Induced Repolarization Abnormalities
}

\author{
KHODOR Nadine $^{\mathrm{a}, \mathrm{b}}$, CARRAULT Guy $^{\mathrm{b}}$, AMOUD Hassan $^{\mathrm{a}}, \mathrm{KHALIL} \mathrm{Mohamad}^{\mathrm{a}}$, L'Hostis Philippe ${ }^{\mathrm{c}}$, HERNANDEZ Alfredo ${ }^{\mathrm{b}}$ \\ ${ }^{a}$ Azm Platform for Research in Biotechnology and its Applications, Electronic Team, Lebanese University, Tripoli, Lebanon \\ ${ }^{\mathrm{b}}$ INSERM, U1099, Rennes, F-35000, France and Université de Rennes 1, LTSI, Rennes, F-35000, France \\ ${ }^{\mathrm{c}}$ Biotrial Core Lab, CS 34246 | 35042 Rennes Cedex | France
}

\begin{abstract}
This study evaluates the predictive values of $\mathrm{T}$ wave morphology parameters reflecting the repolarization changes by beat to beat calculation of parameters using different mathematical tools to identify additional markers sensitive to the variation induced by drug in the surface of the electrocardiogram. T-wave morphology indicators are extracted from nearly 6 hours recordings of two patients from a clinical dSotalol study. The results show that drug induced change in $T$ wave morphology as well as QT interval. In particular, parameters extracted from spherical coordinates of vectrocardiogram that were not tested before for drug effect evaluation show high sensitivity to small change induced by drugs.
\end{abstract}

Keywords-ECG; ventricular repolarization; T-wave morphology; d-Sotalol

\section{INTRODUCTION}

The pharmaceutical industry requires the measure of QT interval during the premarketing phase of drug evaluation. Drug induced prolongation QT interval is the single common use of restriction of drug [1]. However, most arrythmogenic drugs cause not only prolongation of QT corrected interval but also transmural dispersion of action potential duration and thus T-wave modifications [2]. Therefore, others parameters extracted from the T-wave morphology can be useful addition features to characterize repolarization abnormalities and may contribute to drug safety evaluation as well.

The aim of this study is to compare the predictive value of $\mathrm{T}$-wave parameters reflecting the repolarization modifications as well as on the duration but also on the morphology and to identify additional markers sensitive to the variations induced by drug. As illustration, a beat to beat computation in the surface electrocardiogram (ECG) of different features using the d-Sotalol is proposed. The d-Sotalol is a commonly used antiarrythmic drug that has beta blocking action (blocks adrenaline to the heart) and it is used to treat ventricular tachycardia as well as atrial fibrillation. Sotalol leads to increase the action potential duration, refractory period and the QT interval on the surface of ECG [3].

Classical and novel quantitative repolarization features are computed and compared. Each feature reflects the evolution of T-wave morphology before and after administrating the drug. Parameters are based upon different mathematical tools such as principal component analysis (PCA). PCA reduces the 12 leads ECG signal into a minimum dimensional space where the redundancy and the intra-person variability is reduced. We also derive the vectrocardiogram leads from the same transformation to evaluate the interest of other parameters related to vectrocardiogram (VCG) which were not studied before in drug effect evaluation. After the presentation of the database in the next section, the ECG processing is detailed and the different parameters are described. In section III, the results are developed then discussed in section IV to end with a conclusion in section $\mathrm{V}$.

\section{METHODS}

\section{A. Study population}

Standard 12-lead ECG was recorded from two healthy patients (female, Age: 30 and 34 years) during 8 hours for the first woman and 6 hours for the second. Administration of dSotalol was realized after $25 \mathrm{~min}$ from the beginning of recording.

\section{B. ECG processing}

The Electrocardiogram signals were processed using the validated software Segmenta [4], which provides a fully automatic segmentation of all beats based on wavelet transform decomposition and using an evolutionary algorithm to optimize the parameters and threshold of the decision process. Segmenta provides consistently a set of several classical ECG features (RR-interval, QT-interval, PRsegment, QRS duration...) [4].

To study drug influence, each 10 seconds recording was used to form a mean beat in the eight independent leads of the 12 lead ECG (I, II, V1-V6). An SVD was performed on the mean beats to reduce the ECG signal into a minimum space that captures $98 \%$ of the ECG energy. From singular value components, principal component analysis (PCA) was performed [5], the resulting component coefficients were used to project the ECG signal onto the orthogonal eigenvectors. The T-wave of the first principal component lead PC1 was used to analyze the T-wave morphology, the peak and the end point of T-wave. These features were detected using Segmenta, whereas the starting point was approximately calculated as mentioned in [6]. After that, the ST-T segment was filtered using a low pass Kaiser Window FIR filter with $20 \mathrm{~Hz}$ as cut off frequency.

On the other hand, the 8 independent leads were transformed to XYZ leads using the Inverse Dower 
transformation to compute the spherical coordination parameters.

\section{Parameters}

Parameters were classified into four categories: (i) duration parameters; (ii) PCA based parameters; (iii) Morphological parameters and (iv) Parameters related to the spherical coordinates of the VCG.

\section{- Duration parameters measured on PC1 lead}

QTc interval: corrected QT interval was measured where the end of T-wave can usually be clearly distinguished from the beginning of the U-wave, using Fridericia formula:

$$
Q T_{\varepsilon}=\frac{Q T}{\sqrt[8]{R R}}
$$

QRSd: QRS duration which is a time measuring of the QRS complex.

ToTe: Time interval from $\mathrm{T}$-wave onset to $\mathrm{T}$-wave end. TpTe: Time interval from T-wave peak to T-wave end.

\section{- Morphological T-wave parameters}

All these parameters were computed from the T-wave of the PC1 lead [7][8].

Tamp: T-wave amplitude in T-wave peak.

Upslope: Ascending slope of the T-wave. Average value of the slopes at each point of the ascending part of the T-wave.

Downslope: Descending slope of the T-wave. Average value of the slopes at each point of the descending part of the Twave.

Asym: As defined in [7], the asymmetry score of the T-wave computes the difference between the slope profile of the ascending and descending part after normalization of the first derivation of the T-wave and flipping the descending part to cover the ascending part.

$$
A s y m=\frac{\sum_{n=1}^{N} d(n)^{2}}{N}
$$

Where $d(n)$ is the difference between the slope segments at point $n$.

Flatness: The flatness score is a modification of the kurtosis used in statistic. The T-wave area is normalized and the flatness is calculated as:

$$
\text { Flatness }=1-\frac{M_{4}}{M_{2}^{2}}
$$

With $M_{2}$ and $M_{4}$ are the second and the fourth central moments.

Notch: The notch score was obtained after computing the curvature signal from the first and second derivations of $\mathrm{T}$ wave.

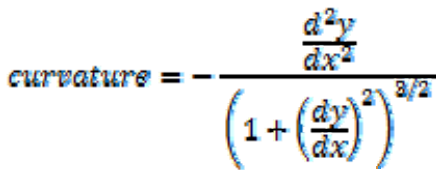

An up-down pair on the curvature signal reflects a real notch where the notch score is expressed as the value of the positive part.

\section{- Principal component analysis based parameter}

After performing PCA on the 8 independent leads, each eigenvalue obtained is a measure of the relevant of the corresponding component. Denoting by $s_{i}$ the eigenvalue of the $i^{\text {th }}$ eigenvector, the following parameters are obtained as:

$$
P C A_{1}=\frac{s_{1}}{\sqrt{\sum_{i=2}^{g} s_{i}^{2}}} \times 100
$$

$$
P C A_{2}=\frac{s_{2}}{s_{1}} \times 100
$$

$$
P C A_{3}=\frac{g_{8}}{s_{1}} \times 100
$$

Several studies have demonstrated that the remaining components (from 4 to 8 ) reflect regional heterogeneity in repolarization [8]. These components are called the nondipolar components and can be expressed as:

ATWR: Absolute T-wave residuum, the absolute value of the sum of last four eigenvalues.

RTWR: relative T-wave residuum, the ratio between the sum of the last four eigenvalues to the sum of all eigenvalues [8].

- Parameters related to the spherical coordinates of VCG The three VCG leads $(\mathrm{X}, \mathrm{Y}, \mathrm{Z})$ are derived from the 12 standard leads of ECG using the inverse Dower transformation, after that spherical coordinates were computed to obtain instantaneous vector magnitude $V_{n}$, azimuth angle $\alpha(n)$ and elevation angle $\beta(n)$ describing the following indicators [9]:

$D E A$ : difference between elevation and azimuth angles

$$
D E A=\frac{1}{N} \sum_{n=1}^{N}|\alpha(n)-\beta(n)|
$$

$R M M V$ : Ratio of maximum to mean vector magnitudes

$$
R M M V=\frac{\max \left(V_{n}\right)}{\operatorname{mean}\left(V_{n}\right)}
$$




\section{RESULTS}

Fig 1 shows the time series of $Q T c$ interval, $D E A, R M M V$ and $P C A 1$ for patient 1 in different recording time computed as described above. Each curve clearly indicates an evolution with time and then drug effect. This evolution appears qualitatively more clearly in the $D E A$ time series. This figure also underlines the sensibility of the features in front the noise. We observe in the $R M M V$ and PCAI time series an abrupt change which is much more reduced in the DEA time series.

PCA was applied for feature selection on a matrix containing the times series of parameters in vector lines. Only parameters contributing in the first three principal components that represent $70 \%$ of total information were retained. Fig 2 and Fig 3 show contribution coefficients of parameters in order of increasing relevance in the first three components for the 2 subjects.

Average and standard deviation values of the remaining parameters were listed in TABLE I for each 1 hour recording where the drug was taken at $8 \mathrm{~h}: 10$. Due to space limitation, only some parameters for the first patient are mentioned. In order to evaluate the significance evolution of each parameter, Friedman test (FT) was applied which is a non parametric statistical test, performed on ranks [10]. FT was used to detect differences in treatments across multiple measures attempts. Unlike the other non parametric test, FT does not require the hypothesis that the samples are independent. In order to decide in which recording a parameter is significantly different from other based upon the mean rank differences of the parameter in each recording that Friedman test calculate, a multiple comparison test was applied after Friedman test once the $p$ value is significant $(p<0.05)$.

All remaining parameters show clear evolution after dSotalol administration. In patient 1, QTc increases significantly from the recording $7 \mathrm{~h}: 55$ where the mean rank $\mathrm{m}_{1}=1.77$ to $\mathrm{m}_{2}=6.96$ at $12 \mathrm{~h}: 55$ than it decreases to $\mathrm{m} 3=5.03$ at 14h:55, $\mathrm{PCA}_{2}$ increases significantly from $\mathrm{m}_{1}=1.52$ at $7 \mathrm{~h}: 55$ to 7.99 at $13 \mathrm{~h}: 55$ then no significant evolution has detected from $13 \mathrm{~h}: 55$ to $14 \mathrm{~h}: 55, R T W R$ increases from $\mathrm{m}_{1}=1.77$ at $7 \mathrm{~h}: 55$ to $\mathrm{m}_{2}=7.69$ at $12 \mathrm{~h}: 55$ then it decreases at $13 \mathrm{~h}: 55$ to $\mathrm{m}_{3}=6.67$, Flatness and downslope increase from $7 \mathrm{~h}: 55$ to $13 \mathrm{~h}: 55$ then no significant evolutions were found, Upslope decreases from $7 \mathrm{~h}: 55$ to $13 \mathrm{~h}: 55$ then it increases from $13 \mathrm{~h}: 55$ to $14 \mathrm{~h}: 55, D E A$ decreases significantly from $7 \mathrm{~h}: 55$ where $\mathrm{m}_{1}=7.99$ to $13 \mathrm{~h}: 55$ where $\mathrm{m}_{2}=1.5$ and increases from $13 \mathrm{~h}: 55$ to $14 \mathrm{~h}: 55, R M M V$ decreases also to $m_{2}=1$ at $13 \mathrm{~h}: 55$ then it increases significantly $\mathrm{m}_{3}=1.9$ at $14 \mathrm{~h}: 55$, Tamp decreases significantly from $\mathrm{m}_{1}=7.68$ at $7 \mathrm{~h}: 55$ to $m_{2}=1$ at $13 \mathrm{~h}: 55$ after that no significant evolution was found, TpTe increases from $7 \mathrm{~h}: 55\left(\mathrm{~m}_{1}=3.57\right)$ to $13 \mathrm{~h}: 55$ $\left(\mathrm{m}_{2}=6.15\right)$ then it decreases to $\mathrm{m}_{3}=4.72$ at $14 \mathrm{~h}: 55$. Patient 2 has mainly the same evolution for all parameters.

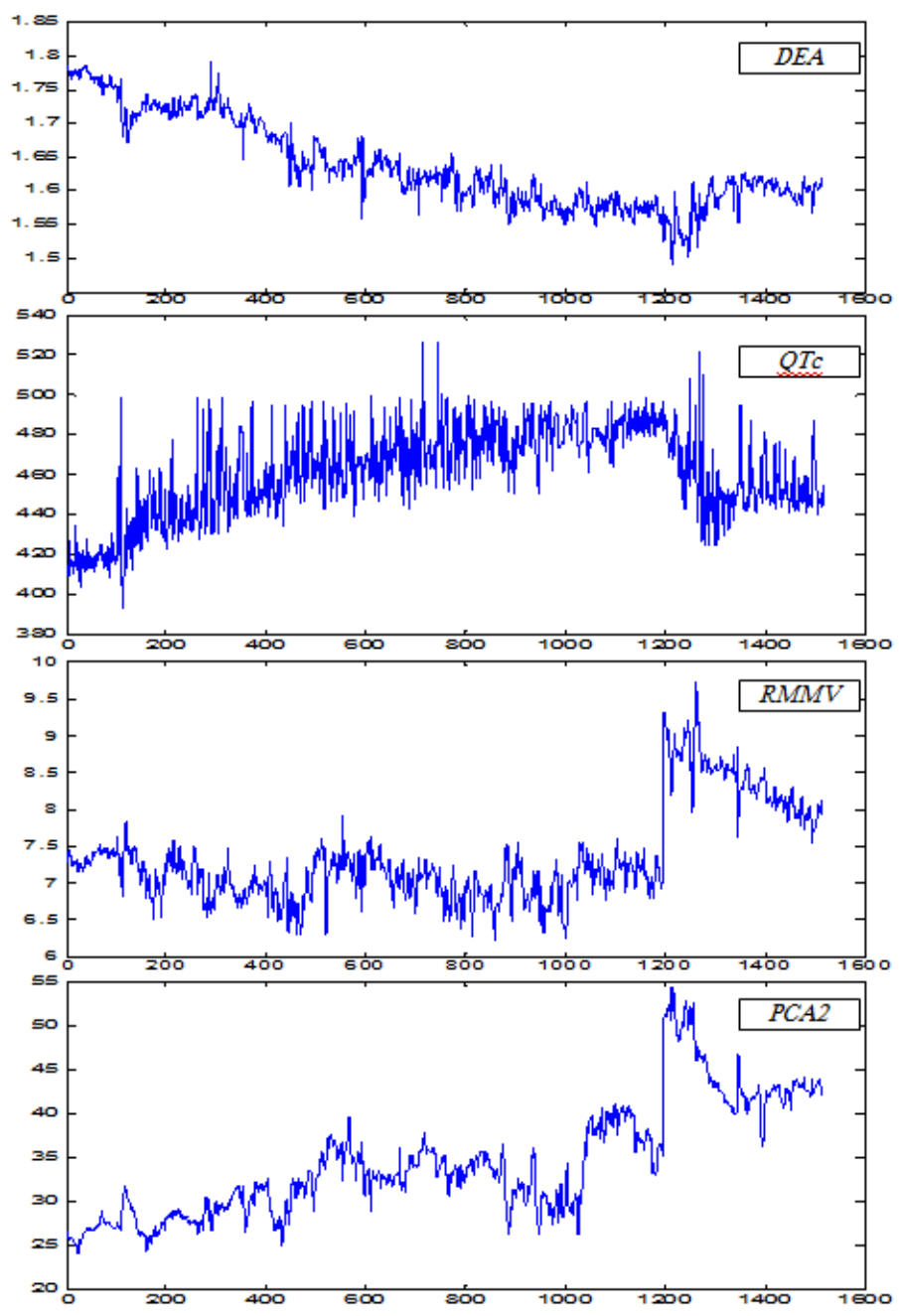

Fig. 1. Time series of $D E A, Q T c, R M M V$ and $P C A 1$ respectively for patient 1

TABLE I. PARAMETER CHANGES IN TIME FOR THE FIRST PATIENT, THE SYMPBOL ‘*’ INDICATES HOURS AFTER D-SOTALOL ADMINISTRATION

\begin{tabular}{|l|l|l|l|l|l|l|l|l|}
\hline & DEA & RMMV & PCA2 & RTWR & Asym & Tamp & Downslope & QTc \\
\hline $\mathbf{0 7 : 5 5}$ & $1.765 \pm 0.01$ & $7.343 \pm 0.1$ & $26.642 \pm 0.94$ & $0.0096 \pm 0.0003$ & $0.153 \pm 0.006$ & $318.077 \pm 11.28$ & $3.179 \pm 0.16$ & $419.385 \pm 11.06$ \\
\hline${ }^{* 08: 55}$ & $1.719 \pm 0.01$ & $7.144 \pm 0.2$ & $27.796 \pm 1.49$ & $0.0097 \pm 0.0007$ & $0.186 \pm 0.03$ & $300.106 \pm 13.63$ & $2.971 \pm 0.16$ & $438.411 \pm 14.51$ \\
\hline${ }^{* 09: 55}$ & $1.701 \pm 0.02$ & $6.88 \pm 0.19$ & $29.531 \pm 1.76$ & $0.0106 \pm 0.0011$ & $0.217 \pm 0.04$ & $277.514 \pm 11.01$ & $2.755 \pm 0.15$ & $455.095 \pm 16.32$ \\
\hline${ }^{*} \mathbf{1 0 : 5 5}$ & $1.640 \pm 0.01$ & $7.083 \pm 0.33$ & $34.047 \pm 2.25$ & $0.0126 \pm 0.0012$ & $0.215 \pm 0.04$ & $237.076 \pm 14.43$ & $2.347 \pm 0.17$ & $466.457 \pm 13.35$ \\
\hline${ }^{* 11: 55}$ & $1.611 \pm 0.02$ & $6.966 \pm 0.26$ & $33.13 \pm 2.07$ & $0.0156 \pm 0.0015$ & $0.228 \pm 0.04$ & $230.876 \pm 10.48$ & $2.226 \pm 0.14$ & $473.975 \pm 13.19$ \\
\hline$* \mathbf{1 2 : 5 5}$ & $1.574 \pm 0.01$ & $7.073 \pm 0.29$ & $35.04 \pm 4.29$ & $0.0182 \pm 0.0017$ & $0.205 \pm 0.05$ & $205.818 \pm 14.66$ & $1.929 \pm 0.18$ & $483.385 \pm 7.95$ \\
\hline$* \mathbf{1 3 : 5 5}$ & $1.590 \pm 0.078$ & $8.746 \pm 0.29$ & $47.079 \pm 4.33$ & $0.0158 \pm 0.0013$ & $0.156 \pm 0.04$ & $152.15 \pm 17.08$ & $1.370 \pm 0.22$ & $455.92 \pm 18.47$ \\
\hline$* \mathbf{1 4 : 5 5}$ & $1.603 \pm 0.01$ & $8.118 \pm 0.23$ & $42.251 \pm 1.86$ & $0.0153 \pm 0.0009$ & $0.195 \pm 0.02$ & $170.662 \pm 7.88$ & $1.664 \pm 0.11$ & $454.565 \pm 11.68$ \\
\hline
\end{tabular}




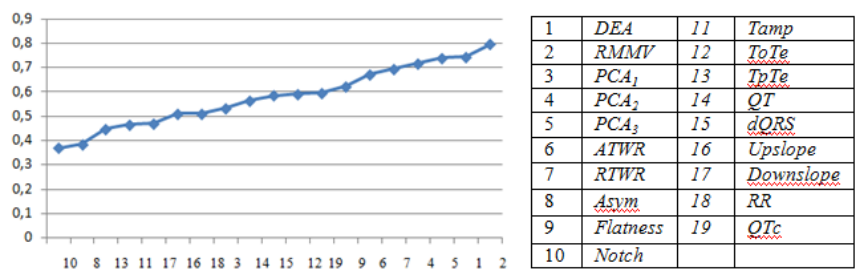

Fig. 2. Parameter contributions in the first 3 components for patient 1 .

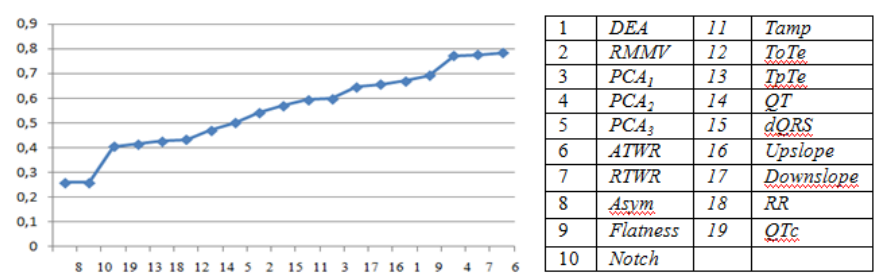

Fig. 3. Parameter contributions in the first 3 components for patient 2 .

\section{DISCUSSION}

After d-Sotalol administration, all parameters derived from the T-wave show clear evolution as the corrected QT interval during time recording. The amplitude of the T-wave was decreased leading to increase the flatness. The decreasing in Upslope and increasing in Downslope can be explained by the increasing of $T p T e$ leading to increase descending segment of the T-wave.

At the end of the recording, the evolution of parameters has changed suggesting that the concentration of d-Sotalol in plasma was reduced. However, not all parameters have the same sensibility with respect to drug concentration. Only some parameters $D E A$ and $R M M V$ have shown significant evolution in patient 1 and maximum evolution in patient 2 passing from the first to the second hour of recording where the effect of dSotalol was still reduced. In parallel some parameters $(Q T c$, Flatness, Tamp, Downslope and PCA2) have showed maximum evolution in early hours then no significant changes was noticed, whereas other parameters still change for the last hours even with reduced concentration of Sotalol (DEA, RMMV, RTWR, TpTe).

\section{CONCLUSION AND PERSPECTIVES}

During the past decade, a number of drugs have had their autorization revised because they induced a prolongation of the QT interval. QT prolongation is now the subject of increased regulatory review and is considered a significant risk factor for drug evaluation.

In this study, we proposed to identify here a set of Twave parameters which can be useful to evaluate drug effect on repolarization. In particular, parameters related to the spherical coordinates $(D E A, R M V V, \ldots)$ of VCG have demonstrated a high sensitivity to small concentration of dSotalol. These results have to be assumed as preliminary due to the limited number of patients. Our current objective is now evaluating the $\mathrm{T}$-wave morphological features in a larger database during longer period. This strategy would be carry out using QT parameters evolution with a placebo and another type of drugs such as moxyfloxacine in order to take into account circadian rhythm.

\section{ACKNOWLEDGMENT}

Authors thank AZM and SAADE Association and Campus France for their fund of this research.

\section{REFERENCES}

[1] D. M. Roden, "Drug-Induced Prolongation of the QT Interval," N. Engl. J. Med., vol. 350, no. 10, pp. 10131022, 2004.

[2] J.-P. Couderc, M. Vaglio, X. Xia, S. Mcnitt, P. Wicker, N. Sarapa, A. J. Moss, and W. Zareba, "Impaired TAmplitude Adaptation to Heart Rate Characterizes $\mathrm{IKr}$ Inhibition in the Congenital and Acquired Forms of the Long QT Syndrome," J. Cardiovasc. Electrophysiol., vol. 18, no. 12, pp. 1299-1305, 2007.

[3] J. L. Anderson and E. N. Prystowsky, "Sotalol: An important new antiarrhythmic," Am. Heart J., vol. 137, no. 3, pp. 388-409, Mar. 1999.

[4] J. Dumont, A. I. Hernandez, and G. Carrault, "Improving ECG Beats Delineation With an Evolutionary Optimization Process," Ieee Trans. Biomed. Eng., vol. 57, no. 3, pp. 607 -615, Mar. 2010.

[5] M. Zabel, B. Acar, T. Klingenheben, M. R. Franz, S. H. Hohnloser, and M. Malik, "Analysis of 12-lead T-wave morphology for risk stratification after myocardial infarction," Circulation, vol. 102, no. 11, pp. 12521257, Sep. 2000.

[6] B. Acar, G. Yi, K. Hnatkova, and M. Malik, "Spatial, temporal and wavefront direction characteristics of 12lead T-wave morphology," Med. Biol. Eng. Comput., vol. 37, no. 5, pp. 574-584, Sep. 1999.

[7] M. P. Andersen, J. Q. Xue, C. Graff, J. K. Kanters, E. Toft, and J. J. Struijk, "New descriptors of T-wave morphology are independent of heart rate," $J$. Electrocardiol., vol. 41, no. 6, pp. 557-561, Nov. 2008.

[8] M. O. Biagetti, P. D. Arini, E. R. Valverde, G. C. Bretran, and R. A. Quinteiro, "Role of dipolar and nondipolar components of the $\mathrm{T}$ wave in determining the T wave residuum in an isolated rabbit heart model," J. Cardiovasc. Electrophysiol., vol. 15, no. 3, pp. 356363, Mar. 2004.

[9] T. Kallert, J.-P. Couderc, A. Voss, and W. Zareba, "Semi-automatic method quantifying $\mathrm{T}$ wave loop morphology: relevance for assessment of heterogeneous repolarization," in Computers in Cardiology, 1999, 1999 , pp. $153-156$.

[10] L. Boschetti, A. Kunzle, P. A. Brivio, and L. Mussio, "Non Parametric Statistical Tests for the Analysis of Multiple-sensor Time Series of Remotely Sensed Data," in IEEE International Conference on Geoscience and Remote Sensing Symposium, 2006. IGARSS 2006, 2006, pp. $200-203$. 